\title{
Right ventricular failure and pathobiology in patients with congenital heart disease - implications for long-term follow-up
}

\author{
Doreen Köhler ${ }^{1+}$, Raoul Arnold ${ }^{1+}$, Tsvetomir Loukanov $^{2}$ and Matthias Gorenflo ${ }^{1 *}$ \\ Department of Pediatric Cardiology, University of Heidelberg, Heidelberg, Germany \\ ${ }^{2}$ Department of Cardiac Surgery, Division of Congenital Cardiac Surgery, University of Heidelberg, Heidelberg, Germany
}

\section{Edited by:}

Cecile Tissot, The University

Children's Hospital, Switzerland

Reviewed by:

Giuseppe Limongelli, Second

University of Naples, Italy

Yves Durandy, Centre Chirurgical

Marie Lannelongue, France

Patrick O. Myers, Geneva University

Hospitals, Switzerland

Dunbar Ivy, University of Colorado

School of Medicine, USA

*Correspondence:

Matthias Gorenflo, Department of Pediatric Cardiology, University of Heidelberg, Im Neuenheimer Feld 430, Heidelberg 69120, Germany e-mail: matthias.gorenflo@med.

uni-heidelberg.de

${ }^{t}$ Doreen Köhler and Raoul Arnold

have contributed equally to this work.
Right ventricular dysfunction represents a common problem in patients with congenital heart defects, such as Tetralogy of Fallot or pulmonary arterial hypertension. Patients with congenital heart defects may present with a pressure or volume overloaded right ventricle $(R V)$ in a bi-ventricular heart or in a single ventricular circulation in which the RV serves as systemic ventricle. Both subsets of patients are at risk of developing right ventricular failure. Obtaining functional and morphological imaging data of the right heart is technically more difficult than imaging of the left ventricle. In contrast to findings on mechanisms of left ventricular dysfunction, very little is known about the pathophysiologic alterations of the right heart. The two main causes of right ventricular dysfunction are pressure and/or volume overload of the RV. Until now, there are no appropriate models available analyzing the effects of pressure and/or volume overload on the RV. This review intends to summarize clinical aspects mainly focusing on the current research in this field. In future, there will be increasing attention to individual care of patients with right heart diseases. Hence, further investigations are essential for understanding the right ventricular pathobiology.

\section{Keywords: right ventricle, congenital heart defects, imaging, surgical techniques, pathobiology}

\section{RIGHT VENTRICULAR FAILURE IN CONGENITAL HEART DISEASE}

In patients with congenital heart disease (CHD), the right ventricle (RV) serves in a bi-ventricular heart as subpulmonal ventricle or in a single ventricular circulation as the systemic ventricle. RV dysfunction is a common problem in the clinical care for patients with CHD. Clinical relevance for research projects in the field of $\mathrm{RV}$ dysfunction is given by the following examples:

Tetralogy of Fallot after intracardiac repair: Volume overload of the RV due to pulmonary regurgitation results in RV dilatation and RV dysfunction. Significant RV dilatation with an end-diastolic volume $>170 \mathrm{ml} / \mathrm{m}^{2}$ or an endsystolic volume $>85 \mathrm{ml} / \mathrm{m}^{2}$ is associated with persistent RV dilatation even after successful surgical pulmonary valve replacement by using a valved homograft (1). Other patients with Tetralogy of Fallot develop a "restrictive RV physiology," which is associated with decreased cardiac output after cardiac surgery and the need for prolonged intensive care.

Univentricular heart with $R V$ predominance: Morphology and function of the systemic ventricle (right versus left) are important factors influencing the long-term prognosis after Fontan type (TCPC, total cavopulmonary connection) repair. Precisely, RV morphology of the systemic ventricle is associated with a much worse outcome and RV dysfunction is associated with higher mortality and morbidity rates in this group of patients (2).

Right ventricular outflow tract obstruction is observed in numerous congenital heart defects (pulmonary valve stenosis, double-chambered RV, etc.). Long persisting RV outflow tract obstruction (RVOTO) will finally lead to systolic and diastolic RV dysfunction.

After atrial repair using the Senning or Mustard techniques in patients with $\mathrm{D}$-transposition of the great arteries (D-TGA) the RV serves as the systemic ventricle. The survival rate of these patients has been reported with $76 \%$ at 20 years of age, the mean age at death was 27 years (3). The function of the systemic RV determines the outcome of these patients (4). The same holds true for unoperated patients with $\mathrm{AV}$ - and VA-discordance (so called congenitally corrected transposition of the great arteries, $c c T G A$ ). In both conditions, adolescents and young adults are prone to RV failure which finally necessitates orthotopic heart transplantation (5).

While the mechanisms of left ventricular dysfunction have been well examined, there is only very limited information available concerning various aspects of RV dysfunction in the setting of chronic volume and/or pressure overload. In contrast, given the low overall mortality of congenital cardiac surgery in neonates and infants, more and more patients will survive into adulthood when there is an increased incidence of RV dysfunction. Therefore, the function of the RV is the major determinant of morbidity and mortality. Nonetheless, precise data on the incidence of RV failure in patients with CHD are lacking. Patients presenting with the RV as the systemic ventricle and patients after surgical repair for tetralogy of Fallot and pulmonary valve insufficiency have the highest risk for developing heart failure (6). In 2006, the "National Heart, Lung, 
and Blood Institute" (National Institutes of Health, Bethesda, MD, USA) therefore addressed the top priority for research on the RV pathophysiology.

Several disease entities predispose to the development of heart failure as a consequence of a dysfunctional RV. In patients after repair of Fallot tetralogy, severe pulmonary regurgitation will lead to RV dilatation and - if not treated adequately - also to left ventricular dysfunction (6). The risk to develop heart failure is even higher in patients with single ventricles after Fontan procedure (7), especially in patients with the RV serving as systemic ventricle, who have the highest risk for RV dysfunction (8).

Cardiac resynchronization therapy (CRT) has been shown to improve mortality and morbidity in adult patients with refractory heart failure and prolonged QRS duration. In children and CHD patients treated with CRT heart failure symptoms have been found to improve at a mean follow-up of 0.7 years (9). However long-term data are lacking and it remains a major challenge to define potential candidates in the subset of patients with $\mathrm{CHD}$ and heart failure who will benefit from CRT as pediatric data from controlled trials are lacking (10).

Currently, stem cell therapy with cardiac progenitor cells (CPCs) is under evaluation in clinical trials (11). Rupp and coworkers could impressively show first results of stem cell therapy in children. In 2010, an infant with hypoplastic left heart syndrome was reported to improve after successful intracoronary administration of autologous bone marrow-derived progenitor cells (12-14).

Taking these features and the consequences for lifelong care for these patients into account, there is a need to initiate research projects addressing the pathophysiology of the RV under the conditions of pressure and/or volume overload.

\section{CHALLENGES OF RIGHT VENTRICULAR IMAGING}

Imaging of the RV aims at obtaining morphological and functional data. The anatomy of the RV makes it more difficult to achieve imaging data on muscle mass as well as ventricular volumes during systole and diastole compared to the left ventricle. Magnetic resonance imaging (MRI) has gained wide acceptance to evaluate RV morphology and function. Imaging of the RV nowadays aims at giving prognostic information for patients with RV volume and/or pressure overload. In patients with a systemic RV, the combination of a RV end-diastolic volume index above $150 \mathrm{ml} / \mathrm{m}^{2}$ (by MRI or multi-detector computed tomography imaging) and data from exercise tests (peak exercise systolic blood pressure below $180 \mathrm{mmHg}$ ) was found to identify patients with a 20 -fold higher annual event rate compared to patients without these risk factors (15).

The right and left ventricle strongly interact. Therefore it is impossible to view abnormalities of the RV without taking the left ventricle into account (16), what had also been shown by an animal model of RV dilatation caused by ischemia. The occlusion of the right coronary artery with intact pericardium resulted in a decrease in LV end-diastolic volume and contractility which was the result of acutely altered RV geometry (17).

In Tetralogy of Fallot, MRI is the gold standard for lifetime imaging (Figure 1A). Echocardiographic parameters such as the tissue Doppler-derived isovolumetric acceleration (IVA) index have been found to correlate with the impaired regional and global longitudinal RV systolic function in a study comparing echocardiographic data with global RV volume and ejection fraction obtained by MRI (18). Comparing echocardiography parameters and MRI data (Figure 1B) remains difficult: parameters obtained by echocardiography such as the myocardial performance index and the isovolumic acceleration index do not correlate with the RV ejection fraction and pulmonary regurgitation fraction derived by cardiac MRI (19).

The RV performance can be reproducibly assessed in patients with Tetralogy of Fallot by measuring the tricuspid annular plane systolic excursion (TAPSE). The correlation of TAPSE with right ventricular ejection fraction (RVEF) is a matter of debate: whereas some groups report a correlation between TAPSE and RVEF in patients with pulmonary arterial hypertension (PAH)

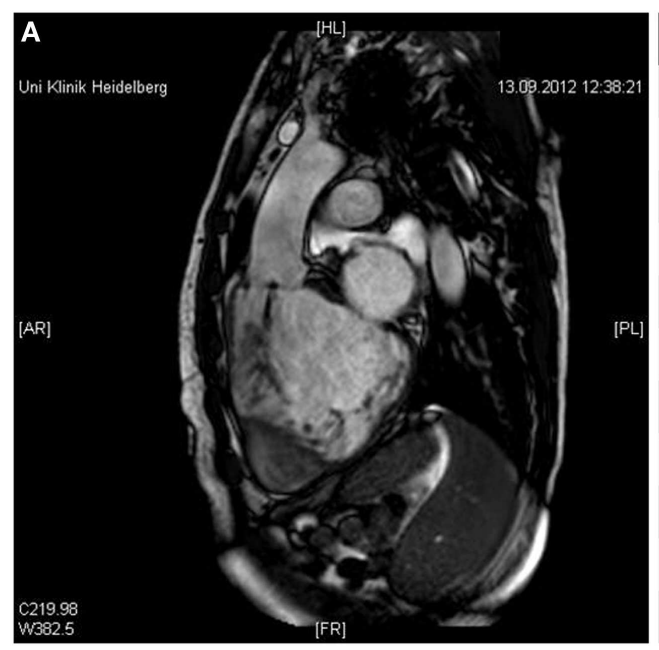

\begin{tabular}{l}
\hline B Main echo/MRI parameters to study RV function \\
Ejection fraction (EF) \\
\hline End-systolic and -diastolic volume (ESV, EDV) \\
\hline Right ventricular outflow tract shortening fraction (RVOT-SF) \\
\hline Right ventricular fractional area change (RVFAC) \\
\hline Tricuspid annular plane systolic excursion (TAPSE) \\
\hline Myocardial performance index (MPI) or Tei index \\
\hline Velocity of the tricuspid anular systolic motion (RV S') \\
\hline Isovolumic relaxation time (IVRT) \\
\hline Pulmonary ejection duration \\
\hline Isovolumetric acceleration at free wall (IVA) \\
Strain and strain rate (SR)
\end{tabular}

FIGURE 1 | (A) Magnetic resonance imaging scan of a patient with ccTGA and dilatation and dysfunction of the systemic right ventricle. (B) Main echocardiographic and MRI parameters to study the function of the right ventricle. 
associated with CHD (20), other groups recently showed that TAPSE cannot be used to determine RVEF and is not associated with exercise performance in patients after repair for Fallot tetralogy (21).

Echocardiography has been described as reproducible and accurate for assessing RV volumes when compared to MRI measurements. However, additional equipment, such as knowledge based reconstruction models like the VentriPoint System ${ }^{\circledR}$, is needed to obtain these data by echocardiography (22).

Tissue Doppler techniques allow the non-invasive estimation of ventricular filling pressures in patients with single RV. It was found that the strain rate strongly correlates with the invasively measured ventricular end-diastolic pressure (23).

New imaging options using tracer techniques are emerging and will give an opportunity for the simultaneous assessment of cardiac performance at different levels in vivo. These techniques will make it possible to assess coronary flow, myocardial perfusion, oxygen delivery, metabolism, and contraction simultaneously (24).

\section{SURGICAL ASPECTS IN CHD WITH RV PRESSURE/VOLUME OVERLOAD}

Surgery in patients with CHD is directed at protecting RV function as long as possible in conditions that present with RV volume and/or pressure overload.

There is evidence suggesting that pulmonary insufficiency and the resulting RV volume overload have detrimental consequences on RV function and clinical parameters such as exercise capacity (25). In addition, RV dilatation due to severe pulmonary regurgitation has been associated with arrhythmias, heart failure, and sudden cardiac death in patients after repair of Fallot tetralogy (26-29).

Although an association of transannular repair in Fallot tetralogy with pulmonary regurgitation and its negative consequences on RV function has been established, the survey published by $\mathrm{Al}$ Habib et al. (25) clearly demonstrates that these techniques are still widely used and probably influenced by anatomical conditions (such as a low $z$-score of the pulmonary valve diameter) which limit the surgical techniques available for palliating the situation. In order to answer the question regarding "the best potential repair" in patients with Fallot tetralogy and hypoplastic pulmonary valve and arteries, a large prospective collaborative investigation would be necessary aiming at acquiring follow-up data extending over several decades (25).

Nevertheless, many centers now recommend early pulmonary valve replacement before first symptoms of heart failure will develop (30).

Implantation of a pulmonary valved conduit is now considered a standard procedure for surgical repair of many complex congenital cardiac anomalies with RVOTO and/or pulmonary insufficiency. However, the degeneration of allogeneic and xenogenic pulmonary valve conduits require repeated conduit replacements during a patient's lifetime. The ideal conduit has not been developed up to now (31).

Xenogenic decellularized tissue-engineered pulmonary valve conduits (TEPVC) recently failed to offer a true advantage and showed a high failure rate (32). Future research is directed at developing autologous valved conduits. Currently, these techniques are under evaluation in animal experiments $(33,34)$.

The correction of residual anatomic defects (e.g., pulmonary regurgitation in patients with Fallot repair) earlier in life seems appropriate given the pathophysiology of RV deterioration in these patients. However, data are lacking evaluating a more conservative and observant regimen until conduit placement versus a concept with earlier surgical intervention.

Acute RV failure is a major risk factor for mortality of patients after orthotopic heart transplantation when pulmonary vascular disease is present such as in chronic left heart failure. An early mortality rate of $19 \%$ has been reported in this subset of patients (35). Reports suggest that the early placement of a RV assist device may serve as a bridge to recovery of patients with RV-failure following heart transplantation $(36,37)$.

There are new surgical techniques on the horizon aiming at improving RV systolic function in patients with dilated RV after surgery for CHD. Tang and coworkers have recently published a mathematical model analyzing the effects of placing an elastic band in the RV on RVEF (38). Therefore, progress in treatment of $\mathrm{RV}$ dysfunction is also expected from modern surgical methods emerging in the future.

\section{EXPERIMENTAL RESEARCH WITH FOCUS ON RV DYSFUNCTION}

Research focusing on RV dysfunction - especially in the context of congenital heart defects - is urgently required. We need to better understand the underlying pathophysiological mechanisms of RV dysfunction in patients with CHD. Even though the RV, when compared to the left ventricle, differs on a morphological, physiological, and molecular level, the RV has gained in scientific interest in the last few years. Extensive work has just begun in order to unravel the etiology of RV dysfunction.

The morphology of the RV, which has a thinner wall than the left ventricle, enables a quick adaptation to changes in preload under physiological conditions. An important mechanism of adaptation of the RV to high pressure is to increase wall thickness by accumulating muscle mass (hypertrophy) and to assume a more rounded shape (39). The cell size is increased due to addition of sarcomeres and an increase in protein synthesis. Protein synthesis in cardiomyocytes is directly induced by stretch and enhanced by autocrine, paracrine, and neurohumoral influences. The increase in afterload is sensed by integrins and stretch-activated ion channels in cardiac cells [myocytes, fibroblasts, endothelial cells (40)]. Integrins are membrane crossing heterodimers that are both firmly attached to the extracellular matrix (ECM) and the cytoskeleton. This allows the transduction of mechanical stress into intracellular chemical signals which are relevant for the synthesis of contractile proteins and proteins for autocrine and paracrine signaling (41, 42). The local response to pressure overload is enhanced in the same way by systemic (neurohumoral) influences, e.g., activation of the renin-angiotensin and sympathetic systems.

The hypertrophic response of cardiomyocytes to pathological conditions leads to changes at the transcriptional level such as an increase of protein synthesis and alterations of fetal genes. Typical markers for fetal gene expression that are merely expressed in fetal ventricles are atrial and brain natriuretic peptides, skeletal 
$\alpha$-actin or $\beta$-myosin heavy chain (43). It was shown in ovine studies that pressure and volume overload alter the expression levels of myocyte enhancer factor 2, GATA-4, Nkx2.5, transcriptional enhancer factor 1 , and specificity protein (Sp) 1 (44). Another elegant study with pulmonary insufficient mice also exhibited altered expression levels of these transcription factors reflecting changes in transforming growth factor (TGF)- $\beta$ signaling, ECM remodeling, and apoptosis (45). One of the hallmarks of maladaptive cardiac growth is the $\alpha$ - to $\beta$-isotype switch of the major thick filament protein myosin heavy chain (MHC) $(\alpha-\mathrm{MHC} / \beta-\mathrm{MHC}$ switch) in cardiomyocytes. In pressure overloaded RV associated with $\mathrm{PAH}$, the $\alpha$-MHC content is reduced from about 30 to $\pm 5 \%$ (46). The adenosine triphosphate-ase (ATPase) activity of $\beta$-MHC is lower than that of $\alpha$-MHC. The disappearance of $\alpha$-MHC results in a significant decrease in systolic function (47). The myocardial regulatory proteins troponin, tropomyosin, and tropomodulin have potential implications in the pathobiology of heart failure $(48,49)$. Their precise role in failure of the RV in conditions associated with volume overload or increased afterload is yet to be analyzed.

The ECM is an essential part of the matrix scaffold of the heart and consists predominantly of collagen with relatively small amounts of fibronectin, laminin, and elastin. The close proximity of the contractile apparatus implies that the ECM influences the systolic and diastolic function as well as ventricular size and shape $(50,51)$. Increased collagen content of the heart (fibrosis) is tightly linked to TGF- $\beta 1$. In addition, the excessive degradation of the matrix by matrix metalloproteinases (MMPs) will adversely affect myocardial systolic and diastolic function (50, 52, 53). The TGF- $\beta 1$ and MMP signaling are linked in a complex fashion (52). Experimental (53) and clinical (46) data show increased fibrosis in the myocardium under conditions of increased pulmonary afterload. At present it remains unclear to what extent these changes are related to RV ischemia and disturbed RV microcirculation. Most of the studies investigating these problems have been conducted with left ventricular strain and failure models, but it is not known how extensively these mechanisms contribute to RV failure.

Angiotensin II (Ang II), Endothelin-1 (ET-1), and other neurohormones are able to induce hypertrophic pathways within the cardiomyocyte, in part, by formation of reactive oxygen species (ROS) (54). In left ventricular failure, increased generation of ROS and reactive nitrogen species (RNS) and a reduced activity of cytoprotective enzymes are documented (55). The contribution of ROS and RNS to RV failure has to be investigated.

Neutrophils may be an important source of excessive ROS formation in heart failure. In parallel with the recruitment of immune cells, proinflammatory cytokines play a complex role in the development of heart failure. Hemodynamic and clinical parameters of disease severity correlate with increased serum levels and expression of the proinflammatory cytokines tumor necrosis factor (TNF)- $\alpha$, interleukin (IL)-1, and IL- 6 by cardiomyocytes (56). Recent data demonstrate that TNF- $\alpha$ has a pivotal role in adverse myocardial remodeling and inhibition of TNF- $\alpha$. The binding protein etanercept can attenuate the progression to heart failure in experimental volume overload (57). A recently detected IL-1related protein, IL-33, is a functional ligand of the IL-1 receptor family member [IL-1 receptor - like protein transmembrane isoform (ST2L)] which is produced by cardiac fibroblasts in response to mechanical strain (58). Increased levels of IL-1 receptor-like protein soluble isoform (sST2) predict mortality and transplantation in patients with chronic heart failure, independent of B-type natriuretic peptide (BNP) or atrial natriuretic peptide (proANP) levels (59). Hitherto, there is no information on the precise role of cardiac inflammation and immune activation in the failing RV. Recent evidence suggests that stimulation of NADPH oxidases (a known target of Ang II and ET-1) and ROS formation may be of critical importance in mediating the slow cardiac response to stretch. The positive inotropic effect of ET-1 requires intact NADPH oxidase activity and protein kinase A (PKA) signaling. The latter may be directly activated by ROS formation, opening the possibility that the NO-redox state of the myocardium may directly affect protein phosphorylation and the inotropic state, independent of adrenergic receptor stimulation (60).

In conditions with increased afterload (i.e., in pulmonary hypertension) the systolic right coronary artery flow is reduced as assessed by MRI (61). There is little information how the RV branches of the right coronary artery adapt to RV remodeling and chronically increased wall stress. Current suggestions favor a similar pattern as observed in the left ventricle: increased oxygen extraction at rest and a higher dependence on increased coronary flow to meet increased myocardial oxygen demand. During cardiac hypertrophy, a mismatch between the numbers of capillaries and the size of the cardiomyocytes can result in myocardial hypoxia, contractile dysfunction, and apoptosis (62). It is not known at present whether microvessels in RV hypertrophy vanish or whether angiogenesis matches the degree of hypertrophy. RV capillary density and vascular endothelial growth factor (VEGF) expression are increased in chronic hypoxic pulmonary hypertension (63).

While cardiomyocyte apoptosis is rare in the normal heart (1 apoptotic cardiomyocyte in $10^{4}$ to $10^{5}$ cells) (64), it has been shown that the apoptosis rate increases up to 1 in 400 cardiomyocytes in human heart failure (65). In the rat model of pulmonary artery banding, the apoptosis rate of RV cardiomyocytes has been shown to be elevated (66). In the mouse model apoptosis has been related to lethal dilated cardiomyopathy (67). There is no information on the impact of chronic RV volume overload on RV cardiomyocyte apoptosis available at present. Blocking apoptosis using broad spectrum caspase inhibitors has been shown to reduce LV ischemia reperfusion injury in the experimental setup $(68,69)$, but currently there is no information on the effect of such treatment on RV structure and function.

Notable analyses of gene expression patterns and epigenetic modifications during maladaptive processes in the heart revealed differences between the left and RV $(70,71)$. Thus, the cardiac biomarkers BNP and ANP have distinct expression patterns in the left and RV of mouse hearts after epigenetically modifications on their promoter regions, such as acetylations and methylations (72). Furthermore, studies with rabbits could impressively demonstrate transcriptional and translational differences between the two chambers of the heart after banding of the thoracic aorta and the pulmonary artery, respectively. Manipulations resulted in altered expression profiles of genes which are involved in energy metabolism, signaling pathways associated with actin, Integrin-linked kinase (ILK), calcium handling, or cardiac tissue development 
(73). MicroRNAs (miRNAs) get more and more into the center of attention in cardiovascular research. Several studies provided information about dysregulated miRNAs, such as miRNA195, miRNA-208, and miRNA-133 in hypertrophic hearts. This evidence may offer new therapeutic opportunities (74).

Congenital heart defects and other diseases associated with RV impairment show a wide variety of causes (Figure 2). Many genes and complex signaling pathways are involved in heart development and processes of heart adaption during altered conditions. So far, efforts in research on RV pathomechanisms had been focused on PAH (75) underscoring the lack of studies concerning other diseases of the right heart. There is an incredible lack in exploring disease mechanisms caused by volume overload on the RV which is especially of importance after the correction of Tetralogy of Fallot.

Until now, there is merely one study known about volume overload of the RV in a small animal model, possibly due to technical difficulties in implementation. Reddy and colleagues generated the first murine model for pulmonary insufficiency and analyzed its physiologic and molecular characteristics. In their model, RV volume overload resulted in declined heart function and altered expression of various genes that are involved in mitochondrial and $\mathrm{G}$ protein-coupled receptor signaling (45). In contrast, few studies with large animal models exist. Recently, researchers analyzed the effects of volume overload (by pulmonary artery shunting) and pressure overload (by pulmonary artery banding), respectively, on the RV in fetal lambs. All animals showed altered expression levels of the transcriptional activators MEF-2, GATA-4, Nkx2.5, SP-1, and SP-3, which are important for early developmental processes (44). In contrast to shunting in lambs, RV volume overload could also be produced by pulmonary insufficiency, e.g., by surgical techniques such as a suture plication of the pulmonary valve leaflets in piglets (76) or in sheep by the widening of the RV outflow tract using a transannular patch (77). In conclusion, scientists should develop models to better understand the pathological processes in the RV as a lot of questions still remain unanswered.

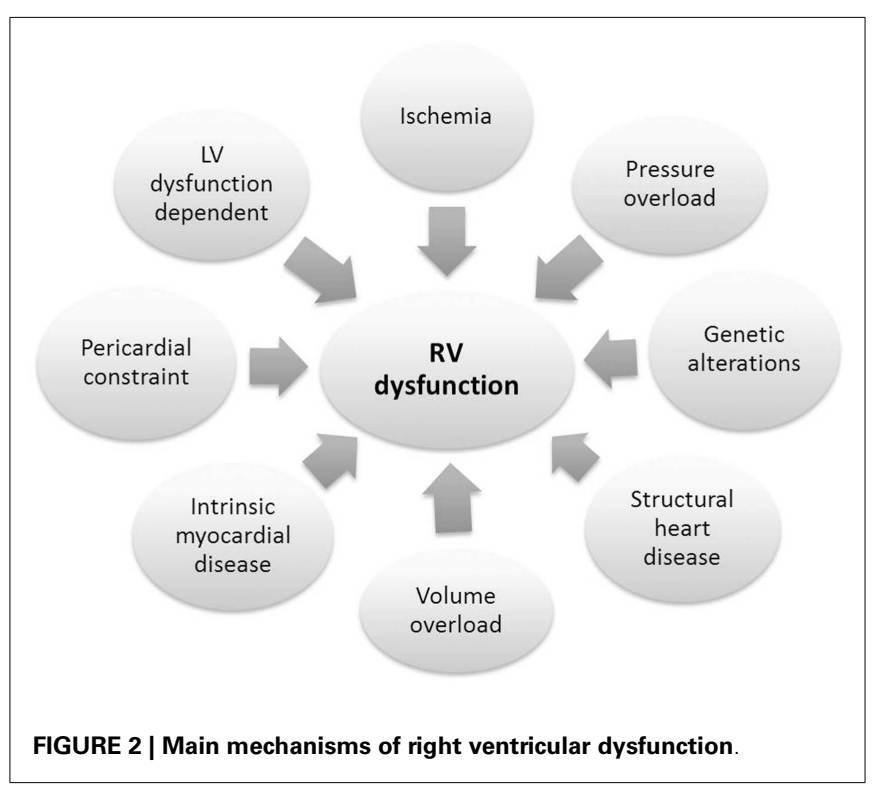

Besides the great advantage of large animal models because of their better comparability to human disease settings and easier implementation of operation techniques, large animals produce high costs and are more laborious in keeping. One of the most important strategies to uncover the etiology of diseases associated with the right heart will be the use of genetic approaches and small animal models. Even conspicuous is the predominant utilization of rodent animal models such as mice and rats based on their many advantages like the presence of a four chambered heart and an extensive knowledge of their genetics (75). The most commonly used rat models to study pulmonary hypertension apply techniques such as monocrotaline (78), hypoxia (79), constriction of the pulmonary artery by banding or clipping $(80,81)$. Fawn hooded rats spontaneously develop a PH phenotype (82).

Current efforts in studying RV pathomechanisms in the setting of experimental PAH generated new interesting findings. Sutendra and colleagues could show that in monocrotaline treated rats the earlier described metabolic shift is not sustained during the development of RV failure (78). Furthermore, Carvedilol is a substance known to reduce RV hypertrophy in experimental PAH. Drake and colleagues analyzed the effect of Carvedilol treatment on rats after development of RV failure using chronic hypoxia and treatment with a VEGF receptor inhibitor. This study displayed an altered gene expression profile thereby revealing the mode of action and mechanisms of RV failure (79).

All these models, however, could not reflect the real clinical presentation of patients with RV dysfunction. The strengths and weaknesses of various animal models emphasize the urgent need for better models to uncover the disease mechanisms in the RV. Mice overexpressing signaling components such as serotonin transporter (SERT), bone morphogenetic protein receptor-2 (BMPR-2), or S100A4 that are involved in right heart failure could only demonstrate details of maladaptive processes in the right heart. More detailed analyses such as investigations in the RV specific ubiquitin-proteasome signaling (83) or analyses of the role of components like cyclooxygenase 2 (84) are needed for gaining deeper insights into right heart diseases. Besides metabolic shifting, ECM remodeling processes are of further interest in research of RV failure in congenital heart defects. For instance, the maladaptive increase of ECM components in the RV of patients in the first weeks after heart transplantation can be found reduced after 3 years (85) underlining the importance of this topic in cardiology. Walker and colleagues discovered changes in the phosphorylation of key contractile proteins, like troponin $\mathrm{T}$, myosin-binding protein $\mathrm{C}$ (MBP-C), and myosin light chain 2 (mlc2) under the setting of pressure overloading in calves (86). These results show once again that RV pathological mechanisms differ from those of the left ventricle, but the knowledge of RV disease mechanisms is still insufficient. A lot of open questions remain such as why metabolic remodeling occurs or whether the immune response in $\mathrm{PAH}$ patients is the cause or consequence of the disease (87).

\section{CONCLUSION}

In the future, RV dysfunction will represent a growing problem due to the increasing number of patients with CHD surviving into adulthood with the morphological RV serving as the systemic ventricle. In addition, patients after pulmonary artery conduit 
implantation are at risk for developing RV dysfunction due to volume or/and pressure overload during their whole lifetime.

At present, most knowledge of RV dysfunction is mainly derived from diseases of the left ventricle. Experimental work has to be performed to obtain more insight into the pathophysiology of RV dysfunction. Modern imaging techniques such as molecular imaging may give more information on the myocardial metabolism during RV dysfunction. Current pharmacological treatment is based on a small panel of drugs, which exert no right heart specific properties. Therefore, future research has to be focused on developing a targeted drug therapy for these patients.

We expect major improvements in the therapy of RV dysfunction by technologies that will enable the placement of smaller ventricular assist devices in patients presenting with acute and chronic right heart failure. Stem cell therapy is another promising therapeutic approach worth mentioning.

However, the knowledge gained by translational and molecular biological research will lead to a more targeted therapy for treating the failing RV.

\section{AUTHORS CONTRIBUTION}

Matthias Gorenflo was responsible for the concept of this manuscript and contributed to major parts of the manuscript. Raoul Arnold contributed to the imaging section. Tsvetomir Loukanov contributed to the section on surgical therapy. Doreen Köhler was responsible for the experimental section of this manuscript and for editing the manuscript.

\section{ACKNOWLEDGMENTS}

This work was supported by a grant from the Siebeneicher Foundation (Imaging of the heart).

\section{REFERENCES}

1. Therrien J, Siu SC, Harris L, Dore A, Niwa K, Janousek J, et al. Impact of pulmonary valve replacement on arrhythmia propensity late after repair of tetralogy of Fallot. Circulation (2001) 103(20):2489-94. doi:10.1161/01.CIR.103.20.2489

2. Khairy P, Fernandes SM, Mayer JE Jr, Triedman JK, Walsh EP, Lock JE, et al. Long-term survival, modes of death, and predictors of mortality in patients with Fontan surgery. Circulation (2008) 117(1):85-92. doi:10.1161/ CIRCULATIONAHA.107.738559

3. Gelatt M, Hamilton RM, McCrindle BW, Connelly M, Davis A, Harris L, et al. Arrhythmia and mortality after the mustard procedure: a 30-year singlecenter experience. J Am Coll Cardiol (1997) 29(1):194-201. doi:10.1016/S07351097(96)00424-X

4. Roos-Hesselink JW, Meijboom FJ, Spitaels SE, van Domburg R, van Rijen EH, Utens EM, et al. Decline in ventricular function and clinical condition after Mustard repair for transposition of the great arteries (a prospective study of 22-29 years). Eur Heart J (2004) 25(14):1264-70. doi:10.1016/j.ehj.2004.03.009

5. Sarkar D, Bull C, Yates R, Wright D, Cullen S, Gewillig M, et al. Comparison of long-term outcomes of atrial repair of simple transposition with implications for a late arterial switch strategy. Circulation (1999) 100(19 Suppl):II176-81. doi:10.1161/01.CIR.100.suppl_2.II-176

6. Dinardo JA. Heart failure associated with adult congenital heart disease. Semin Cardiothorac Vasc Anesth (2013) 17(1):44-54. doi:10.1177/1089253212469841

7. Norozi K, Wessel A, Alpers V, Arnhold JO, Geyer S, Zoege M, et al. Incidence and risk distribution of heart failure in adolescents and adults with congenital heart disease after cardiac surgery. Am J Cardiol (2006) 97(8):1238-43. doi:10.1016/j.amjcard.2005.10.065

8. Anderson PA, Sleeper LA, Mahony L, Colan SD, Atz AM, Breitbart RE, et al. Contemporary outcomes after the Fontan procedure: a Pediatric Heart Network Multicenter Study. J Am Coll Cardiol (2008) 52(2):85-98. doi:10.1016/j. jacc.2008.01.074
9. Cecchin F, Frangini PA, Brown DW, Fynn-Thompson F, Alexander ME, Triedman JK, et al. Cardiac resynchronization therapy (and multisite pacing) in pediatrics and congenital heart disease: five years experience in a single institution. J Cardiovasc Electrophysiol (2009) 20(1):58-65. doi:10.1111/j.1540-8167.2008. 01274.x

10. Dubin AM, Janousek J, Rhee E, Strieper MJ, Cecchin F, Law IH, et al. Resynchronization therapy in pediatric and congenital heart disease patients an international multicenter study. J Am Coll Cardiol (2005) 46(12):2277-83. doi:10.1016/j.jacc.2005.05.096

11. Files MD, Boucek RJ. 'Shovel-ready' applications of stem cell advances for pediatric heart disease. Curr Opin Pediatr (2012) 24(5):577-83. doi:10.1097/MOP. 0b013e328357a4cf

12. Pincott ES, Burch M. Potential for stem cell use in congenital heart disease. Future Cardiol (2012) 8(2):161-9. doi:10.2217/fca.12.13

13. Rupp S, Zeiher AM, Dimmeler S, Tonn T, Bauer J, Jux C, et al. A regenerative strategy for heart failure in hypoplastic left heart syndrome: intracoronary administration of autologous bone marrow-derived progenitor cells. J Heart Lung Transplant (2010) 29(5):574-7. doi:10.1016/j.healun.2009.10.006

14. Rupp S, Bauer J, Tonn T, Schachinger V, Dimmeler S, Zeiher AM, et al. Intracoronary administration of autologous bone marrow-derived progenitor cells in a critically ill two-yr-old child with dilated cardiomyopathy. Pediatr Transplant (2009) 13(5):620-3. doi:10.1111/j.1399-3046.2008.01024.x

15. van der Bom T, Winter MM, Groenink M, Vliegen HW, Pieper PG, van Dijk AP, et al. Right ventricular end-diastolic volume combined with peak systolic blood pressure during exercise identifies patients at risk of complications in adults with a systemic right ventricle. J Am Coll Cardiol (2013) 62(10):926-36. doi:10.1016/j.jacc.2013.06.026

16. Sheehan F, Redington A. The right ventricle: anatomy, physiology and clinical imaging. Heart (2008) 94(11):1510-5. doi:10.1136/hrt.2007.132779

17. Brookes C, Ravn H, White P, Moeldrup U, Oldershaw P, Redington A. Acute right ventricular dilatation in response to ischemia significantly impairs left ventricular systolic performance. Circulation (1999) 100(7):761-7. doi:10.1161/01.CIR. 100.7.761

18. Abd El Rahman MY, Hui W, Schuck R, Rentzsch A, Berger F, Gutberlet M, et al. Regional analysis of longitudinal systolic function of the right ventricle after corrective surgery of tetralogy of Fallot using myocardial isovolumetric acceleration index. Pediatr Cardiol (2013) 34(8):1848-53. doi:10.1007/s00246-013-0726-0

19. Koca B, Oztunc F, Eroglu AG, Gokalp S, Dursun M, Yilmaz R. Evaluation of right ventricular function in patients with tetralogy of Fallot using the myocardial performance index and isovolumic acceleration: a comparison with cardiac magnetic resonance imaging. Cardiol Young (2013). doi:10.1017/ S1047951113000504

20. Koestenberger M, Nagel B, Avian A, Ravekes W, Sorantin E, Cvirn G, et al. Systolic right ventricular function in children and young adults with pulmonary artery hypertension secondary to congenital heart disease and tetralogy of Fallot: tricuspid annular plane systolic excursion (TAPSE) and magnetic resonance imaging data. Congenit Heart Dis (2012) 7(3):250-8. doi:10.1111/j.1747-0803. 2012.00655.x

21. Mercer-Rosa L, Parnell A, Forfia PR, Yang W, Goldmuntz E, Kawut SM. Tricuspid annular plane systolic excursion in the assessment of right ventricular function in children and adolescents after repair of tetralogy of Fallot. J Am Soc Echocardiogr (2013) 26(11):1322-9. doi:10.1016/j.echo.2013.06.022

22. Dragulescu A, Grosse-Wortmann L, Fackoury C, Mertens L. Echocardiographic assessment of right ventricular volumes: a comparison of different techniques in children after surgical repair of tetralogy of Fallot. Eur Heart J Cardiovasc Imaging (2012) 13(7):596-604. doi:10.1093/ejechocard/jer278

23. Husain N, Gokhale J, Nicholson L, Cheatham JP, Holzer RJ, Cua CL. Noninvasive estimation of ventricular filling pressures in patients with single right ventricles. J Am Soc Echocardiogr (2013) 26(11):1330-6. doi:10.1016/j. echo.2013.08.002

24. Osterholt M, Sen S, Dilsizian V, Taegtmeyer H. Targeted metabolic imaging to improve the management of heart disease. JACC Cardiovasc Imaging (2012) 5(2):214-26. doi:10.1016/j.jcmg.2011.11.009

25. Al Habib HF, Jacobs JP, Mavroudis C, Tchervenkov CI, O’Brien SM, Mohammadi S, et al. Contemporary patterns of management of tetralogy of Fallot: data from the society of thoracic surgeons database. Ann Thorac Surg (2010) 90(3):813-9. doi:10.1016/j.athoracsur.2010.03.110

26. Bove EL, Byrum CJ, Thomas FD, Kavey RE, Sondheimer HM, Blackman MS, et al. The influence of pulmonary insufficiency on ventricular function following 
repair of tetralogy of Fallot. Evaluation using radionuclide ventriculography. J Thorac Cardiovasc Surg (1983) 85(5):691-6.

27. Zahka KG, Horneffer PJ, Rowe SA, Neill CA, Manolio TA, Kidd L, et al. Longterm valvular function after total repair of tetralogy of Fallot. Relation to ventricular arrhythmias. Circulation (1988) 78(5 Pt 2):III14-9.

28. Bouzas B, Kilner PJ, Gatzoulis MA. Pulmonary regurgitation: not a benign lesion. Eur Heart J (2005) 26(5):433-9. doi:10.1093/eurheartj/ehi091

29. Therrien J, Siu SC, McLaughlin PR, Liu PP, Williams WG, Webb GD. Pulmonary valve replacement in adults late after repair of tetralogy of Fallot: are we operating too late? J Am Coll Cardiol (2000) 36(5):1670-5. doi:10.1016/S0735-1097(00) 00930-X

30. Geva T. Indications and timing of pulmonary valve replacement after tetralogy of Fallot repair. Semin Thorac Cardiovasc Surg Pediatr Card Surg Annu (2006) 9(1):11-22.

31. Forbess JM. Conduit selection for right ventricular outflow tract reconstruction: contemporary options and outcomes. Semin Thorac Cardiovasc Surg Pediatr Card Surg Annu (2004) 7:115-24. doi:10.1053/j.pcsu.2004.02.004

32. Perri G, Polito A, Esposito C, Albanese SB, Francalanci P, Pongiglione G, et al. Early and late failure of tissue-engineered pulmonary valve conduits used for right ventricular outflow tract reconstruction in patients with congenital heart disease. Eur J Cardiothorac Surg (2012) 41(6):1320-5. doi:10.1093/ejcts/ezr221

33. Nakayama Y, Yahata Y, Yamanami M, Tajikawa T, Ohba K, Kanda K, et al. A completely autologous valved conduit prepared in the open form of trileaflets (type VI biovalve): mold design and valve function in vitro. J Biomed Mater Res B Appl Biomater (2011) 99(1):135-41. doi:10.1002/jbm.b.31880

34. Takewa Y, Yamanami M, Kishimoto Y, Arakawa M, Kanda K, Matsui Y, et al. In vivo evaluation of an in-body, tissue-engineered, completely autologous valved conduit (biovalve type VI) as an aortic valve in a goat model. $J$ Artif Organs (2013) 16(2):176-84. doi:10.1007/s10047-012-0679-8

35. Hosenpud JD, Bennett LE, Keck BM, Boucek MM, Novick RJ. The registry of the international society for heart and lung transplantation: seventeenth official report-2000. J Heart Lung Transplant (2000) 19(10):909-31. doi:10.1016/S1053-2498(00)00138-8

36. Bajona P, Salizzoni S, Brann SH, Coyne J, Bermudez C, Kormos R, et al. Prolonged use of right ventricular assist device for refractory graft failure following orthotopic heart transplantation. J Thorac Cardiovasc Surg (2010) 139(3):e53-4. doi:10.1016/j.jtcvs.2008.10.042

37. Hodge AB, Yeager CJ, Preston TJ, Savage AJ, Butts RJ, Kavarana MN. The Thoratec CentriMag for pediatric right ventricular failure. J Extra Corpor Technol (2013) 45(2):133-5.

38. Tang D, Yang C, Geva T, Rathod R, Yamauchi H, Gooty V, et al. A multiphysics modeling approach to develop right ventricle pulmonary valve replacement surgical procedures with a contracting band to improve ventricle ejection fraction. Comput Struct (2013) 122:78-87. doi:10.1016/j.compstruc.2012.11.016

39. Bogaard HJ, Abe K, Vonk Noordegraaf A, Voelkel NF. The right ventricle under pressure: cellular and molecular mechanisms of right-heart failure in pulmonary hypertension. Chest (2009) 135(3):794-804. doi:10.1378/chest.08-0492

40. Mann DL. Basic mechanisms of left ventricular remodeling: the contribution of wall stress. J Card Fail (2004) 10(6 Suppl):S202-6. doi:10.1016/j.cardfail.2004. 09.008

41. Katsumi A, Orr AW, Tzima E, Schwartz MA. Integrins in mechanotransduction. J Biol Chem (2004) 279(13):12001-4. doi:10.1074/jbc.R300038200

42. Ross RS, Pham C, Shai SY, Goldhaber JI, Fenczik C, Glembotski CC, et al. Beta1 integrins participate in the hypertrophic response of rat ventricular myocytes. Circ Res (1998) 82(11):1160-72. doi:10.1161/01.RES.82.11.1160

43. Kuwahara K, Nishikimi T, Nakao K. Transcriptional regulation of the fetal cardiac gene program. J Pharmacol Sci (2012) 119(3):198-203. doi:10.1254/jphs. 12R04CP

44. Azakie A, Fineman J, He Y. Differential responses of the right ventricle to abnormal loading conditions in vivo: possible pathophysiologic mechanisms. J Thorac Cardiovasc Surg (2013) 145(5):1335-44. doi:10.1016/j.jtcvs.2013.01.016

45. Reddy S, Zhao M, Hu DQ, Fajardo G, Katznelson E, Punn R, et al. Physiologic and molecular characterization of a murine model of right ventricular volume overload. Am J Physiol Heart Circ Physiol (2013) 304(10):H1314-27. doi:10.1152/ajpheart.00776.2012

46. Lowes BD, Minobe W, Abraham WT, Rizeq MN, Bohlmeyer TJ, Quaife RA, et al. Changes in gene expression in the intact human heart. Downregulation of alpha-myosin heavy chain in hypertrophied, failing ventricular myocardium. J Clin Invest (1997) 100(9):2315-24. doi:10.1172/JCI119770
47. Herron TJ, McDonald KS. Small amounts of alpha-myosin heavy chain isoform expression significantly increase power output of rat cardiac myocyte fragments. Circ Res (2002) 90(11):1150-2. doi:10.1161/01.RES.0000022879.57270.11

48. Adamcova M, Sterba M, Simunek T, Potacova A, Popelova O, Mazurova Y, et al. Troponin as a marker of myocardiac damage in drug-induced cardiotoxicity. Expert Opin Drug Saf (2005) 4(3):457-72. doi:10.1517/14740338.4.3.457

49. VanBuren P, Okada Y. Thin filament remodeling in failing myocardium. Heart Fail Rev (2005) 10(3):199-209. doi:10.1007/s10741-005-5250-8

50. Janicki JS, Brower GL, Gardner JD, Forman MF, Stewart JA Jr, Murray DB, et al. Cardiac mast cell regulation of matrix metalloproteinase-related ventricular remodeling in chronic pressure or volume overload. Cardiovasc Res (2006) 69(3):657-65. doi:10.1016/j.cardiores.2005.10.020

51. Baicu CF, Stroud JD, Livesay VA, Hapke E, Holder J, Spinale FG, et al. Changes in extracellular collagen matrix alter myocardial systolic performance. Am J Physiol Heart Circ Physiol (2003) 284(1):H122-32. doi:10.1152/ajpheart.00233.2002

52. Khan R, Sheppard R. Fibrosis in heart disease: understanding the role of transforming growth factor-beta in cardiomyopathy, valvular disease and arrhythmia. Immunology (2006) 118(1):10-24. doi:10.1111/j.1365-2567.2006.02336.x

53. Weber KT, Pick R, Janicki JS, Gadodia G, Lakier JB. Inadequate collagen tethers in dilated cardiopathy. Am Heart J (1988) 116(6 Pt 1):1641-6. doi:10.1016/ 0002-8703(88)90763-6

54. Giordano FJ. Oxygen, oxidative stress, hypoxia, and heart failure. J Clin Invest (2005) 115(3):500-8. doi:10.1172/JCI24408

55. Yet SF, Perrella MA, Layne MD, Hsieh CM, Maemura K, Kobzik L, et al. Hypoxia induces severe right ventricular dilatation and infarction in heme oxygenase-1 null mice. J Clin Invest (1999) 103(8):R23-9. doi:10.1172/JCI6163

56. Mann DL. Inflammatory mediators and the failing heart: past, present, and the foreseeable future. Circ Res (2002) 91(11):988-98. doi:10.1161/01.RES. $0000043825.01705 .1 \mathrm{~B}$

57. Jobe LJ, Melendez GC, Levick SP, Du Y, Brower GL, Janicki JS. TNF-alpha inhibition attenuates adverse myocardial remodeling in a rat model of volume overload. Am J Physiol Heart Circ Physiol (2009) 297(4):H1462-8. doi:10.1152/ ajpheart.00442.2009

58. Sanada S, Hakuno D, Higgins LJ, Schreiter ER, McKenzie AN, Lee RT. IL-33 and ST2 comprise a critical biomechanically induced and cardioprotective signaling system. J Clin Invest (2007) 117(6):1538-49. doi:10.1172/JCI30634

59. Weinberg EO, Shimpo M, Hurwitz S, Tominaga S, Rouleau JL, Lee RT. Identification of serum soluble ST2 receptor as a novel heart failure biomarker. Circulation (2003) 107(5):721-6. doi:10.1161/01.CIR.0000047274.66749.FE

60. Zhang YH, Dingle L, Hall R, Casadei B. The role of nitric oxide and reactive oxygen species in the positive inotropic response to mechanical stretch in the mammalian myocardium. Biochim Biophys Acta (2009) 1787(7):811-7. doi:10.1016/j.bbabio.2009.03.020

61. van Wolferen SA, Marcus JT, Westerhof N, Spreeuwenberg MD, Marques KM, Bronzwaer JG, et al. Right coronary artery flow impairment in patients with pulmonary hypertension. Eur Heart J (2008) 29(1):120-7. doi:10.1093/eurheartj/ ehm567

62. Tomanek RJ. Response of the coronary vasculature to myocardial hypertrophy. J Am Coll Cardiol (1990) 15(3):528-33. doi:10.1016/0735-1097(90)90620-5

63. Partovian C, Adnot S, Eddahibi S, Teiger E, Levame M, Dreyfus P, et al. Heart and lung VEGF mRNA expression in rats with monocrotaline- or hypoxia-induced pulmonary hypertension. Am J Physiol (1998) 275(6 Pt 2):H1948-56.

64. Soonpaa MH, Field LJ. Survey of studies examining mammalian cardiomyocyte DNA synthesis. Circ Res (1998) 83(1):15-26. doi:10.1161/01.RES.83.1.15

65. Hein S, Arnon E, Kostin S, Schonburg M, Elsasser A, Polyakova V, et al. Progression from compensated hypertrophy to failure in the pressure-overloaded human heart: structural deterioration and compensatory mechanisms. Circulation (2003) 107(7):984-91. doi:10.1161/01.CIR.0000051865.66123.B7

66. Braun MU, Szalai P, Strasser RH, Borst MM. Right ventricular hypertrophy and apoptosis after pulmonary artery banding: regulation of $\mathrm{PKC}$ isozymes. Cardiovasc Res (2003) 59(3):658-67. doi:10.1016/S0008-6363(03)00470-X

67. Wencker D, Chandra M, Nguyen K, Miao W, Garantziotis S, Factor SM, et al. A mechanistic role for cardiac myocyte apoptosis in heart failure. J Clin Invest (2003) 111(10):1497-504. doi:10.1172/JCI17664

68. Yaoita H, Ogawa K, Maehara K, Maruyama Y. Attenuation of ischemia/reperfusion injury in rats by a caspase inhibitor. Circulation (1998) 97(3):276-81. doi:10.1161/01.CIR.97.3.276

69. Holly TA, Drincic A, Byun Y, Nakamura S, Harris K, Klocke FJ, et al. Caspase inhibition reduces myocyte cell death induced by myocardial ischemia and 
reperfusion in vivo. J Mol Cell Cardiol (1999) 31(9):1709-15. doi:10.1006/jmcc. 1999.1006

70. Drake JI, Bogaard HJ, Mizuno S, Clifton B, Xie B, Gao Y, et al. Molecular signature of a right heart failure program in chronic severe pulmonary hypertension. Am J Respir Cell Mol Biol (2011) 45(6):1239-47. doi:10.1165/rcmb.20100412OC

71. Haddad F, Ashley E, Michelakis ED. New insights for the diagnosis and management of right ventricular failure, from molecular imaging to targeted right ventricular therapy. Curr Opin Cardiol (2010) 25(2):131-40. doi:10.1097/HCO. 0b013e328335febd

72. Mathiyalagan P, Chang L, Du XJ, El-Osta A. Cardiac ventricular chambers are epigenetically distinguishable. Cell Cycle (2010) 9(3):612-7. doi:10.4161/cc.9.3. 10612

73. Friehs I, Cowan DB, Choi YH, Black KM, Barnett R, Bhasin MK, et al. Pressureoverload hypertrophy of the developing heart reveals activation of divergent gene and protein pathways in the left and right ventricular myocardium. Am J Physiol Heart Circ Physiol (2013) 304(5):H697-708. doi:10.1152/ajpheart.00802. 2012

74. van Rooij E, Olson EN. MicroRNAs: powerful new regulators of heart disease and provocative therapeutic targets. J Clin Invest (2007) 117(9):2369-76. doi:10.1172/JCI33099

75. Archer SL, Weir EK, Wilkins MR. Basic science of pulmonary arterial hypertension for clinicians: new concepts and experimental therapies. Circulation (2010) 121(18):2045-66. doi:10.1161/CIRCULATIONAHA.108.847707

76. Agger P, Hyldebrandt JA, Nielsen EA, Hjortdal V, Smerup M. A novel porcine model for right ventricular dilatation by external suture plication of the pulmonary valve leaflets - practical and reproducible. Interact Cardiovasc Thorac Surg (2010) 10(6):962-6. doi:10.1510/icvts.2009.227264

77. Yerebakan C, Klopsch C, Niefeldt S, Zeisig V, Vollmar B, Liebold A, et al. Acute and chronic response of the right ventricle to surgically induced pressure and volume overload - an analysis of pressure-volume relations. Interact Cardiovasc Thorac Surg (2010) 10(4):519-25. doi:10.1510/icvts.2009.221234

78. Sutendra G, Dromparis P, Paulin R, Zervopoulos S, Haromy A, Nagendran J, et al. A metabolic remodeling in right ventricular hypertrophy is associated with decreased angiogenesis and a transition from a compensated to a decompensated state in pulmonary hypertension. J Mol Med (Berl) (2013) 91(11):1315-27. doi:10.1007/s00109-013-1059-4

79. Drake JI, Gomez-Arroyo JG, Dumur CI, Kraskauskas D, Natarajan R, Bogaard HJ, et al. Chronic carvedilol treatment partially reverses the right ventricular failure transcriptional profile in experimental pulmonary hypertension. Physiol Genomics (2013) 45(12):449-61. doi:10.1152/physiolgenomics. 00166.2012

80. Bogaard HJ, Mizuno S, Hussaini AA, Toldo S, Abbate A, Kraskauskas D, et al. Suppression of histone deacetylases worsens right ventricular dysfunction after pulmonary artery banding in rats. Am J Respir Crit Care Med (2011) 183(10):1402-10. doi:10.1164/rccm.201007-1106OC
81. Kreymborg K, Uchida S, Gellert P, Schneider A, Boettger T, Voswinckel R, et al. Identification of right heart-enriched genes in a murine model of chronic outflow tract obstruction. J Mol Cell Cardiol (2010) 49(4):598-605. doi:10.1016/j.yjmcc.2010.07.014

82. Kim KH, Kim YJ, Lee SP, Kim HK, Seo JW, Sohn DW, et al. Survival, exercise capacity, and left ventricular remodeling in a rat model of chronic mitral regurgitation: serial echocardiography and pressure-volume analysis. Korean Circ J (2011) 41(10):603-11. doi:10.4070/kcj.2011.41.10.603

83. Rajagopalan V, Zhao M, Reddy S, Fajardo GA, Wang X, Dewey S, et al. Altered ubiquitin-proteasome signaling in right ventricular hypertrophy and failure. Am J Physiol Heart Circ Physiol (2013) 305(4):H551-62. doi:10.1152/ajpheart. 00771.2012

84. Loukanov T, Jaschinski C, Kirilov M, Klimpel H, Karck M, Gorenflo M. Cyclooxygenase- 2 expression in lung in patients with congenital heart malformations and pulmonary arterial hypertension. Thorac Cardiovasc Surg (2013) 61(4):307-11. doi:10.1055/s-0033-1337446

85. Schupp DJ, Huck BP, Sykora J, Flechtenmacher C, Gorenflo M, Koch A, et al. Right ventricular expression of extracellular matrix proteins, matrixmetalloproteinases, and their inhibitors over a period of 3 years after heart transplantation. Virchows Arch (2006) 448(2):184-94. doi:10.1007/s00428-0050050-z

86. Walker LA, Walker JS, Glazier A, Brown DR, Stenmark KR, Buttrick PM. Biochemical and myofilament responses of the right ventricle to severe pulmonary hypertension. Am J Physiol Heart Circ Physiol (2011) 301(3):H832-40. doi:10.1152/ajpheart.00249.2011

87. Voelkel NF, Gomez-Arroyo J, Abbate A, Bogaard HJ, Nicolls MR. Pathobiology of pulmonary arterial hypertension and right ventricular failure. Eur Respir J (2012) 40(6):1555-65. doi:10.1183/09031936.00046612

Conflict of Interest Statement: The authors declare that the research was conducted in the absence of any commercial or financial relationships that could be construed as a potential conflict of interest.

Received: 31 July 2013; accepted: 04 November 2013; published online: 19 November 2013.

Citation: Köhler D, Arnold R, Loukanov T and Gorenflo M (2013) Right ventricular failure and pathobiology in patients with congenital heart disease - implications for long-term follow-up. Front. Pediatr. 1:37. doi: 10.3389/fped.2013.00037

This article was submitted to Pediatric Cardiology, a section of the journal Frontiers in Pediatrics.

Copyright () 2013 Köhler, Arnold, Loukanov and Gorenflo. This is an open-access article distributed under the terms of the Creative Commons Attribution License (CC $B Y)$. The use, distribution or reproduction in other forums is permitted, provided the original author(s) or licensor are credited and that the original publication in this journal is cited, in accordance with accepted academic practice. No use, distribution or reproduction is permitted which does not comply with these terms. 